\title{
Observations of superimposed ice formation at melt-onset on fast ice on Kongsfjorden, Svalbard
}

\author{
Marcel Nicolaus ${ }^{\text {a,* }}$, Christian Haas ${ }^{\text {a }}$, Jörg Bareiss ${ }^{\mathrm{b}}$ \\ a Alfred Wegener Institute for Polar and Marine Research, Bremerhaven, Germany \\ ${ }^{\mathrm{b}}$ University of Trier, Department of Climatology, Trier, Germany
}

Received 1 January 2003; received in revised form 20 June 2003; accepted 8 August 2003

\begin{abstract}
Measurements of superimposed ice formation and snow properties as a function of the surface energy balance during melt-onset are presented. They were performed on fast ice on Kongsfjorden, Svalbard, between late May and early June 2002. On May 27, rapid snow melt commenced and within 5 days the snow cover initially $0.23 \mathrm{~m}$ thick transformed completely into $0.05-0.06 \mathrm{~m}$ of superimposed ice. The superimposed ice formed by both percolation of melt water to ice layers and by settling of snow between ice layers. Melt-onset was characterized by rapid changes in the total energy balance, which became positive throughout the whole day after May 27. The increased energy fluxes were mainly caused by higher incoming longwave radiation due to overcast conditions. The observations show that superimposed ice contributes significantly to sea ice mass balance.
\end{abstract}

(C) 2003 Elsevier Ltd. All rights reserved.

Keywords: Superimposed ice; Sea ice; Energy balance; Snow properties

\section{Introduction}

Sea ice and its snow cover are important elements of the climate system. Due to its insulating effect, snow on sea ice strongly modifies the surface energy balance of the coupled atmosphere-ice-ocean system. However, during winter, particularly in Antarctica snow contributes significantly to the sea ice mass balance through the formation of snow ice (e.g. Eicken et al., 1995; Jeffries et al., 1997). This results from the re-freezing of slush at the snow/ice interface caused by sea water flooding in the case of negative ice freeboard. Also during summer snow contributes to the sea ice mass balance by the formation of superimposed ice (Onstott, 1992; Holt and Digby, 1985; Kawamura et al., 1997; Haas et al., 2001). This results from the re-freezing of snow melt water at the snow/ice interface when the temperature gradients within snow and ice are positive, e.g. the ice is colder than the freezing temperature of freshwater. Hence superimposed ice is different from sea ice and snow ice because it consists only of freshwater ice.

\footnotetext{
${ }^{*}$ Corresponding author. Tel.: +49-471-4831-1753.

E-mail address: mnicolaus@awi-bremerhaven.de (M. Nicolaus).
}

Similarly, superimposed ice forms on glaciers, and affects their mass and energy balance as well as their radar scattering properties (Koerner, 1970; König et al., 2001).

On Antarctic sea ice superimposed ice can form layers with a few decimeters in thickness (Haas, 2001; Kawamura et al., 1997) due to a relatively thick snow cover (Massom et al., 1997) and moderate snow melt rates (Andreas and Ackley, 1982).

Superimposed ice also forms in the Arctic, but usually it rapidly deteriorates shortly after formation due to strong surface ablation (Barber et al., 1998; Holt and Digby, 1985). Gerland et al. (1999) described the development of superimposed ice on Kongsfjorden during the spring summer transition. Based on their observations and excellent logistic accessibility, Kongsfjorden was also chosen as area of investigation for our study, even if it differs from the typical Arctic Ocean regime. The fjord is characterized by a sharp transition from meteorological winter to summer conditions in May and June, when mean air temperature varies between -5 and $0{ }^{\circ} \mathrm{C}$. Sea ice covers the fjord during winter, whereas it is ice-free in summer. Mean monthly precipitation is about $30 \mathrm{~mm}$. A more detailed description of the physical environment of Kongsfjorden can be found in Svendsen et al. (2002). 
Besides physical objectives, superimposed ice formation strongly affects the evolution of sea ice biological communities in early summer, because highly light absorbing snow is transformed into an almost clear layer of ice. This increases the availability of photosynthetically active radiation (PAR) below and in the ice (Winther et al., submitted for publication).

However, the boundary conditions for superimposed ice formation on sea ice have not yet been studied. Here we present time series measurements of superimposed ice formation and snow properties as a function of the associated surface energy balance.

\section{Measurements}

Glaciological and meteorological measurements were performed on $0.78 \mathrm{~m}$ thick fast ice on Kongsfjorden at $78.96^{\circ} \mathrm{N} 12.26^{\circ} \mathrm{E}$ (Fig. 1) during a two-week period from May 20 to June 04 2002. The location was selected close to Gerdøya, where instrument setup was safest, because the ice cover lasts until July, and the snow conditions are representative for the eastern Kongsfjord region. During daily visits to the site several observations of snow and ice properties were carried out. Measurements usually started at 10:00 (all times are local time) and lasted between 2 and $24 \mathrm{~h}$, depending on weather conditions and snow property variations.

Snow thickness was measured with a spacing of $1.0 \mathrm{~m}$ along a $50 \mathrm{~m}$ representative profile with the aid of a ruler stick once a day at 12:00. Vertical profiles of snow temperature and wetness were measured in usually three snow pits along the profile with spacing of $0.05 \mathrm{~m}$ in hourly intervals. Snow temperature was determined with a hand held Pt100 thermometer and snow wetness was measured with a dielectric resonator probe (TOIKKA Snow Fork, Espoo, Finland; Sihvola and Tiuri, 1986) in percentage liquid water content. The density of the snow cover was obtained by weighing of a defined volume (0.5 l) of snow.

Spectral albedo was recorded with a Spectron Engineering SE 590 (Denver, USA) spectroradiometer at 256 wavelengths between 396 and $1075 \mathrm{~nm}$. Additionally, ice cores were drilled on 9 days at different positions of the snow thickness profile to measure sea ice thickness as well as vertical profiles of temperature and salinity. Crystal texture was observed by means of thick sections viewed between crossed polarizors. This also revealed the thickness of superimposed ice. For comparison, an additional ice core obtained in March 2002 at the southern shore of Kongsfjord was included in the analysis (Gerland, personal communication).

For continuous observations of meteorological and radiation boundary conditions a meteorological station was installed $10 \mathrm{~m}$ away from the profile for snow and ice measurements. The snow underneath and beside the instruments was not disturbed in order to keep the homogeneous surface, equal for all sensors. Global $\left(S_{\downarrow}\right)$ and reflected $\left(S^{\uparrow}\right)$ short-wave radiation was determined with up- and down-looking Kipp \& Zonen CM 22

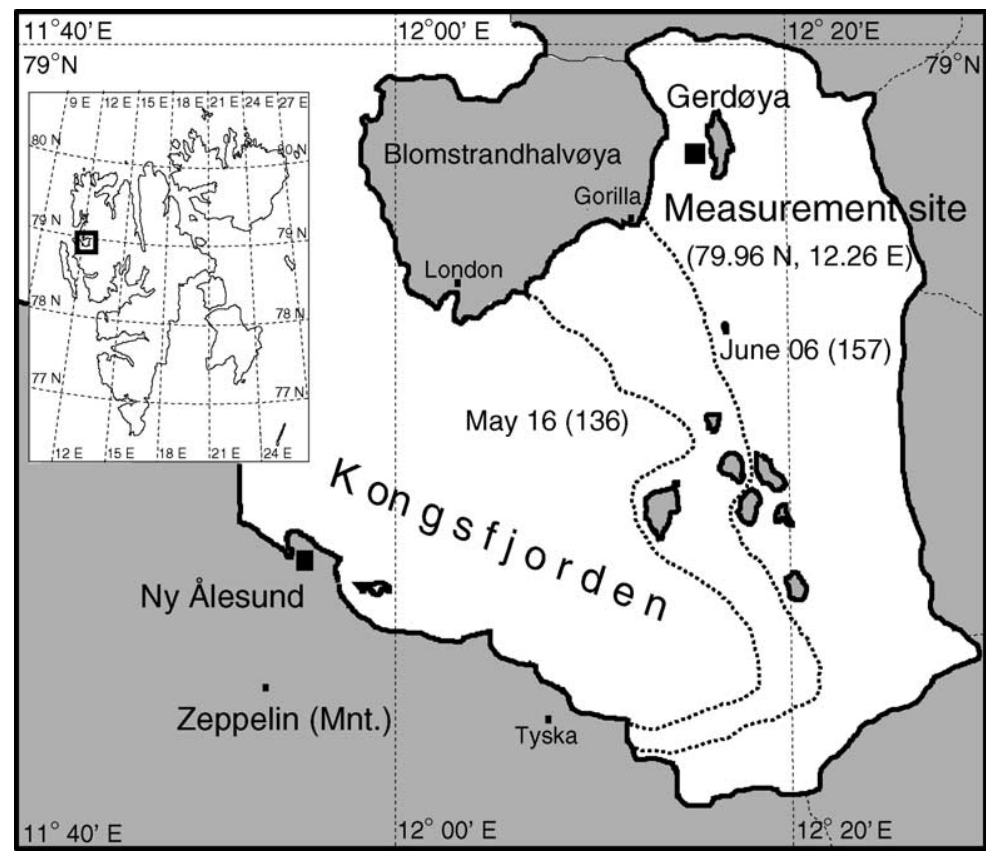

Fig. 1. Map of Kongsfjorden showing the location of the measurement site and the fast ice edges (dotted lines) on May 16 and June 62002 taken from air photographs. 
(Delft, Netherlands) pyranometers. Similarly, incoming $\left(L_{\downarrow}\right)$ and outgoing $\left(L^{\uparrow}\right)$ long-wave radiation was measured with two Eppley (Newport, USA) pyrgeometers.

Air temperature, relative humidity as well as wind velocity and direction were measured with an Automatic Weather Station (AWS, Thies-Klima, Göttingen, Germany) $2 \mathrm{~m}$ above the snow surface. Control measurements of the dry- and wet-bulb temperature were frequently carried out using an Assmann psychrometer. They indicated significantly biased temperature values of the AWS, caused by radiation and wind chill effects, such that air temperatures from Koldewey Station (Ny Ålesund, Fig. 1) were used for further analysis. From these meteorological measurements, turbulent heat fluxes $\left(Q_{\text {turb }}\right)$ were derived using the aerodynamic approach (Launiainen and Cheng, 1995). The total energy balance $(Q)$ at the air/snow interface was computed as

$Q=S_{\downarrow}-S^{\uparrow}+L_{\downarrow}-L^{\uparrow}+Q_{\text {turb }}$.

It is positive for a net energy flux into the snow. Ocean heat fluxes were not measured and are neglected here.

\section{Results}

The observation period was characterized by two distinct meteorological phases with clear sky before May 27 and overcast conditions thereafter. The change was mainly represented by a drastic $70 \mathrm{~W} / \mathrm{m}^{2}$ increase of the incoming longwave radiation on May 27 (Fig. 2a). This resulted in a shift of the energy balance, remaining positive even at low sun elevation (Fig. 2b). As a consequence, air temperature remained positive, too, as plotted in Fig. 2c. Turbulent fluxes were negligible during the observation period due to very calm wind conditions.

At pre-melt conditions before May 27, the entire snow cover was below the melting point and even if local

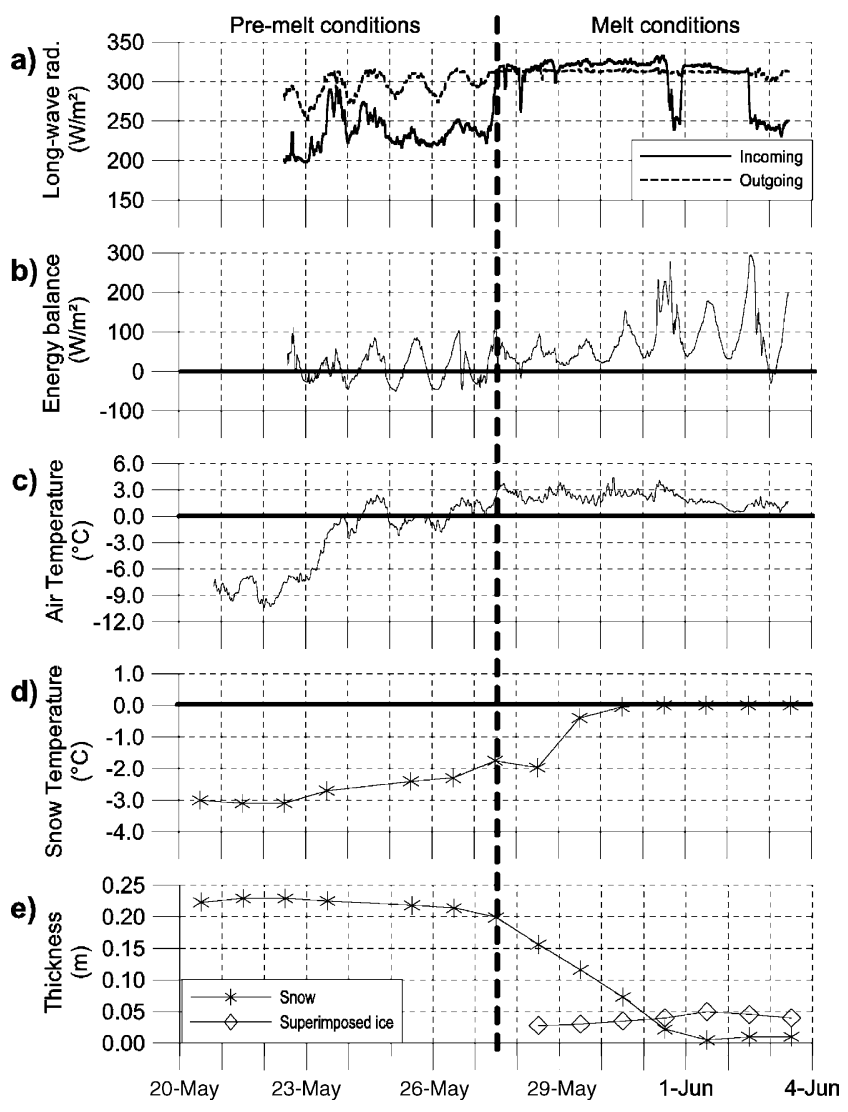

Fig. 2. Time series of incoming and outgoing long-wave radiation (a), total energy balance (b), $2 \mathrm{~m}$ air temperature (c), snow temperature at the snow/ice interface (d) as well as thickness of snow cover and superimposed ice as observed on Kongsfjorden sea ice (e). The dashed line on May 27 demarcates melt-onset.

and/or temporal melting occurred at the surface it re-froze again during the night. The snow thickness did not change (Fig. 2d) and temperature profiles contained a pronounced diurnal cycle (an extract is plotted in Fig. 3a) with a constant snow/ice interface temperature of $-3.0^{\circ} \mathrm{C}$ (see additionally Fig. 2d).
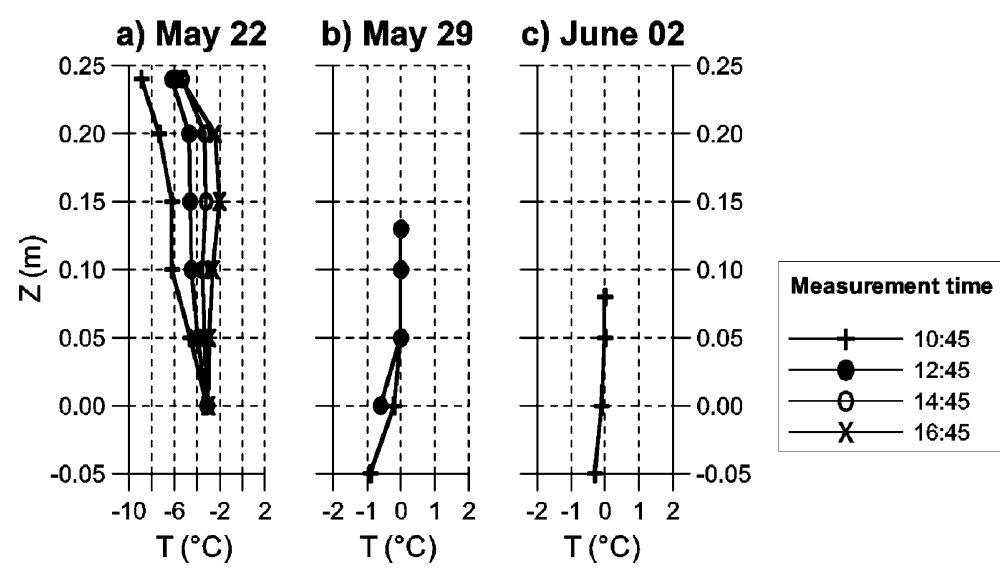

Fig. 3. Vertical snow and uppermost ice temperature profiles for typical late-winter (a), melt-onset (b) and melt conditions (c). $Z=0 \mathrm{~m}$ refers to snow/ice interface and the topmost data point is at snow surface. 
After May 27 the snow thinned rapidly, decreasing from a thickness of 0.23 to $0.02 \mathrm{~m}$ within 5 days (Fig. 2e). The surface snow layers did not anymore re-freeze in the diurnal cycle and temperature at the snow/ice interface quickly approached $0{ }^{\circ} \mathrm{C}$ (Fig. 2d) after May 27. Hence, May 27 demarcated melt-onset.

After melt-onset the melting front progressed downwards through the snow pack towards the underlying snow/ice interface $(Z=0)$. The negative temperature gradient had reversed and the topmost snow layers reached their melting point, leading to a rapid decrease in snow thickness. On May 31 the melting front had reached the ice surface. The isothermal snow melted rapidly, while total sea ice thickness increased by $0.06-$ $0.84 \mathrm{~m}$ due to upward growth of superimposed ice. Minimum temperatures within the ice remained at $-1.8^{\circ} \mathrm{C}$ at a depth of $0.5 \mathrm{~m}$ until the end of the observations (Figs. 2e and 3).

Before superimposed ice formation commenced the ice surface at the measurement site had positive freeboard of $5 \mathrm{~mm}$. Therefore no surface flooding by sea water and snow ice formation occurred during the observation period. On May 28, one day after melt-onset, $25 \mathrm{~mm}$ of superimposed ice were observed directly on top of the sea ice surface for the first time. The layer grew up to a thickness of 50-60 mm until June 1 (Fig. 2e). Then, it began to deteriorate due to continued melting after the snow had disappeared. The additional ice layer increased the freeboard to $65 \mathrm{~mm}$.

Before melt-onset, the snow pack was dry $\left(<0.2 \% \%_{\mathrm{vol}}\right)$ at all depths (Fig. 4). On May 27 raised wetness was observed in surface and bottom layers, reaching a mean of $3.3 \%$ vol. Afterwards further melting caused water contents up to $11 \%_{\mathrm{vol}}$. The last measurements, when

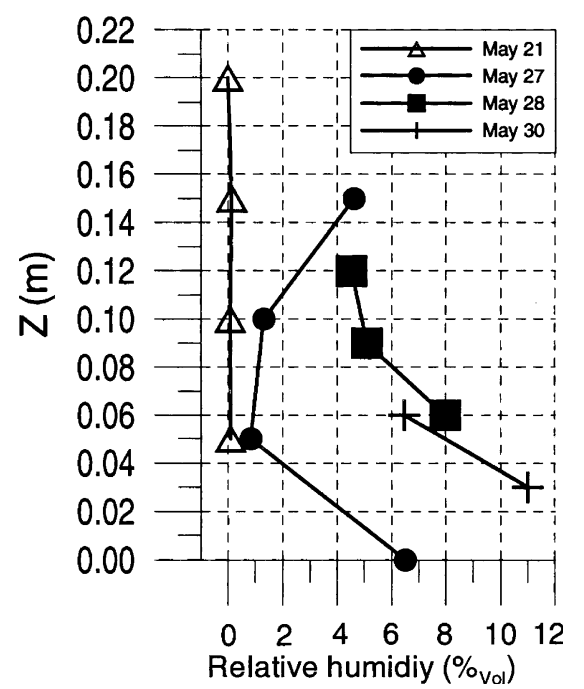

Fig. 4. Snow wetness profiles for late-winter conditions (May 21), melt-onset (May 27), enhanced melting and superimposed ice formation (May 28 and 30). $Z=0 \mathrm{~m}$ refers to snow/ice interface and the topmost data point is at snow the surface.

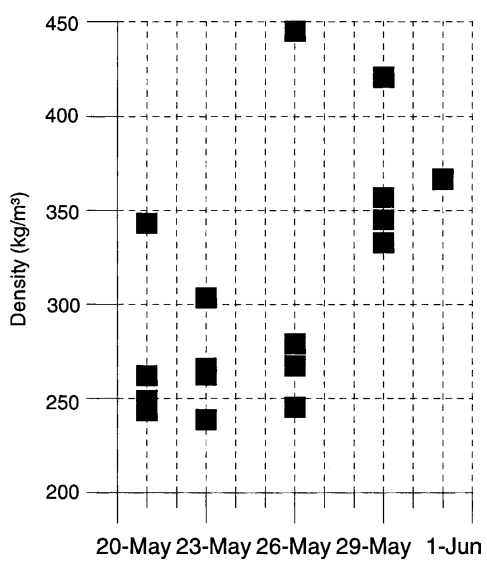

Fig. 5. Time series of snow density. Every data point corresponds to the density of a snow sample taken at different depths in up to three snow pits per day. The sample depths were chosen in order to represent the main stratigraphic units.

only $0.06 \mathrm{~m}$ of snow were left, showed a mean wetness of $8.7 \%$ vol (May 30).

Initial mean snow density was $268 \pm 50 \mathrm{~kg} / \mathrm{m}^{3}$ before May 25 (averaged over all depths and several snow pits) (Fig. 5). After melt-onset, it increased to $366 \pm 40 \mathrm{~kg} / \mathrm{m}^{3}$ on May 30. However, densities were generally highest in the icy bottom layers.

Snow grain size increased from $<1 \mathrm{~mm}$ within the initially dry snow to $2-3 \mathrm{~mm}$ on May 30 , shortly before the snow vanished completely. However, the initial snow cover was well stratified. At least two 5-20 mm thick ice layers could be identified within the lowest $60 \mathrm{~mm}$ in many snow pits, although their hardness or degree of iciness was laterally variable. Between these ice layers loose layers of small rounded grains of $1 \mathrm{~mm}$ in diameter were found. Above this icy section at the bottom soft snow was present with only few and very thin and discontinuous ice layers in between.

In the final phase, when all snow had disappeared, the surface was covered by a snow-like layer of large polygonal grains of 5-15 mm diameter. This layer originated from the deteriorating superimposed ice.

The wetting and decaying of snow is also reflected in changes of the spectral albedo (Fig. 6). Initially mean albedo amounted to 0.9 for all wavelengths between 396 and $1074 \mathrm{~nm}$ until May 27. The increased wetness on May 29 caused a reduction of the near-infrared (>900 nm) albedo to 0.55 . On the last days, albedo of the snow-free, deteriorated superimposed ice surface was below 0.7 for all wavelengths.

In Fig. 7a salinity profiles of three ice cores obtained on Kongsfjorden between March and June are presented. The March data show a C-shaped profile with raised salinities in the top and bottom, typical for young ice. The mean salinity was $9.0 \mathrm{ppt}$. Although the core was taken at a different location, we assume that its salinity is representative for the initial fast ice salinity at 


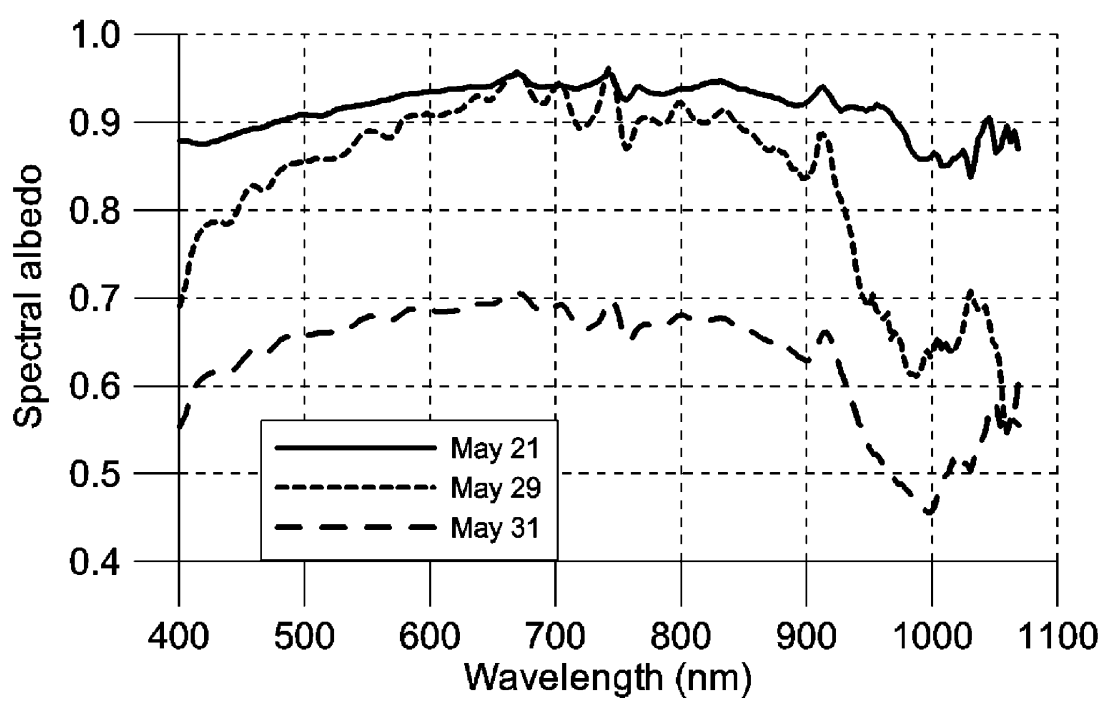

Fig. 6. Spectral albedo for typical late-winter (May 22), melt-onset (May 29) and melt conditions (May 31).
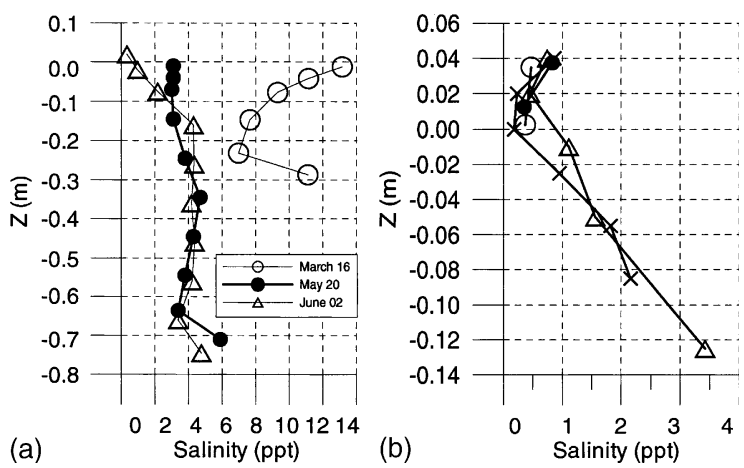

Fig. 7. Salinity profiles of complete ice cores drilled on March 16, May 20 and June 2 (a) and surface ice cores obtained on June 2 (b). Data are plotted at center positions of individual core segments with respect to the water level $(Z=0 \mathrm{~m})$. Note different scales of axes in both plots.

Gerdøya, too. Between March and May the typical desalination of the ice due to brine rejection can be seen, resulting in a mean salinity of $4.0 \mathrm{ppt}$ on May 20 . After melt-onset (core from June 02) salinity in the topmost $0.15 \mathrm{~m}$ was low with a mean of $1.9 \mathrm{ppt}$, due to the presence of superimposed ice and further desalination forced by warming. But the mean salt content of the whole ice core was still similar at 3.9 ppt. The profiles agree well with profiles obtained by Gerland et al. (1999) in the same region and period of the year.

Salinity profiles of surface cores including superimposed ice are shown with higher vertical resolution in Fig. $7 b$. The cores have been obtained on June 02. The salinity of superimposed ice $(Z>0)$ is generally below $1.0 \mathrm{ppt}$, and the profiles closely resemble those of Antarctic ice cores presented by Haas et al. (2001). The slightly raised salinities at the very top probably result from salt contamination during coring, segmentation (in slices of $0.1 \mathrm{~m}$ length) and sample transport, which was difficult under the warm conditions. Hence salinity of superimposed ice is probably $<0.5$.

There is also evidence for the presence of $0.15 \mathrm{~m}$ of snow ice at the original ice surface, as the salinity of the May 20 ice core was slightly lower at the surface (3.1 ppt) than the underlying congelation ice $(4.1 \mathrm{ppt})$ even before melt-onset. This is also underlined by its finegrained, orbicular granular crystal texture, with a sharp interface to columnar ice underneath. The snow ice has probably formed during early spring, when the sea ice was still thin and its surface could be depressed below the water level, leading to flooding.

The sequence of melt/freeze metamorphosed snow over newly formed superimposed ice and the underlying sea ice typical for early melt conditions is illustrated in Fig. 8. In the photograph the $35 \mathrm{~mm}$ thick layer of superimposed ice can be recognized from its transparent appearance with numerous air bubbles (Fig. 8, white arrow) of various size. These bubbles appear partly white because they were filled with snow during thicksection preparation. The photograph also shows that the topmost centimeters of the original sea ice/snow ice were very porous (Fig. 8, black arrow). This porous layer very much resembles the initial phases of gap layers also typical for late summer Antarctic sea ice (Haas et al., 2001).

\section{Discussion}

Our observations show that melt-onset was mainly initiated by an increase in incoming long-wave radiation due to overcast weather conditions, which led to a positive energy balance. As a consequence melting commenced at the surface and increased the snow 


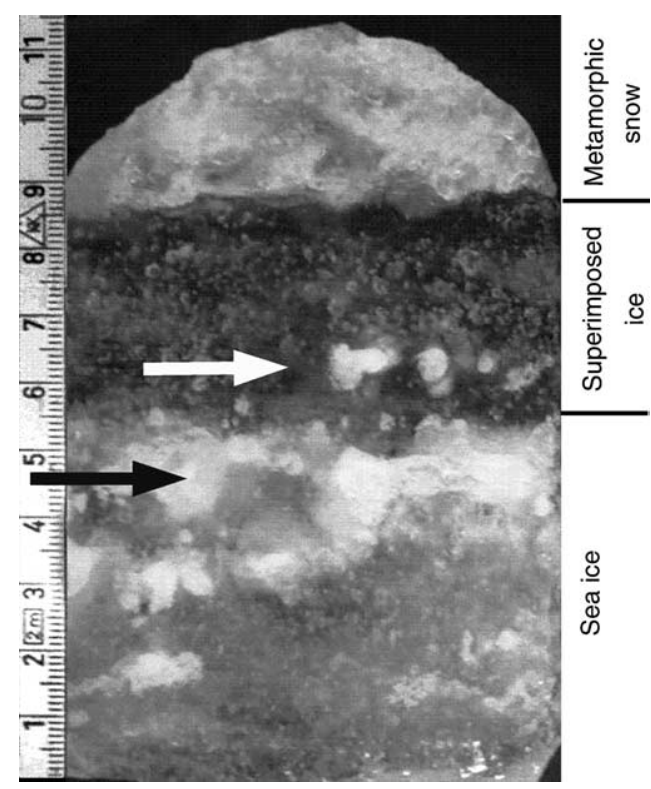

Fig. 8. Photograph of a vertical thick-section form May 30 showing the typical sequence of metamorphic snow, superimposed ice and sea ice. The white arrow points to air bubbles within the superimposed ice and the black one to a region of high porosity in the sea ice below. The scale is in $0.01 \mathrm{~m}$.

wetness until melt water percolated downwards to the colder sea ice surface or ice layers within the inhomogeneous snow cover. At these impermeable interfaces the melt water accumulated, and re-froze to form superimposed ice.

Although every spring/summer transition has different meteorological conditions we believe that the same processes occur every year. This is confirmed by Gerland et al. (1999) who also observed the presence of superimposed ice shortly after the onset of melt. However, formation of superimposed ice could progress much slower with less dramatic changes of the energy balance, and sometimes might be interrupted if the weather conditions return to late winter/spring conditions.

Superimposed ice formation seems to be generally typical for snow beginning to melt on sea ice, because the lower temperatures further below will always cause re-freezing of the melt water if it can not drain through cracks or off floe edges. The process is confirmed by our observations of the temporal development of temperature, wetness, and density. However, our observations of snow and ice stratigraphy are not detailed enough to distinguish between melt water percolation or snow settling and the merging of initially separated ice layers. These are probably very important processes, too. For example, the characteristic layers with horizontally elongated air bubbles within the superimposed ice (white arrow in Fig. 8) seem to represent former layers of loose snow located between two distinct ice layers. The above mentioned, widespread icy layers are common for Svalbard and other Arctic regions, too, and result from winter warm events. They subdivide the snow cover before melt-onset and form impermeable barriers for melt water percolation. Therefore, percolation through the entire snow cover to the snow/ice interface might in fact play a minor role for superimposed ice formation. It is probably sufficient if the wetness above these ice layers becomes big enough by percolation so that rapid grain growth can take place (Colbeck, 1987) simultaneously in various depths, and if the different ice layers merge by settling.

In total $0.23 \mathrm{~m}$ of snow were completely transformed into $0.05-0.06 \mathrm{~m}$ of superimposed ice. As mass conservation should apply, the final superimposed ice thickness should correspond to the initial snow thickness weighted by the density difference between snow and superimposed ice. In fact, if we assume a superimposed ice density of $850 \mathrm{~kg} / \mathrm{m}^{3}$ taking into account the presence of many air bubbles, then the $0.23 \mathrm{~m}$ of $268 \mathrm{~kg} / \mathrm{m}^{3}$ snow will be transformed to $73 \mathrm{~mm}$ of superimposed ice. The differences with our observations might be explained by inaccurate density measurements or by sublimation, or by some lateral heterogeneity.

When the melt water re-freezes to form superimposed ice latent heat is released and conducted downwards into the colder sea ice. This heat contributes to an accelerated warming of the upper sea ice layers. Probably this warming causes partial melting and increased brine volumes within the uppermost sea ice and results in the formation of porous layers underneath the superimposed ice. In Antarctica, these porous or gap layers are a prominent feature, and are important for supporting high standing stocks of algae (Haas et al., 2001). Interestingly, as shown in Fig. 8 (black arrow) and discussed above, also on Kongsfjorden the porosity underneath the superimposed ice was significantly increased, pointing to a close relation between superimposed ice and gap layer formation.

Furthermore the transformation of $0.23 \mathrm{~m}$ of radiation absorbing snow into nearly transparent ice is of significant importance for biological production underneath and within sea ice. This can increase the transmittance of PAR (i.e. $300-700 \mathrm{~nm}$ ) by a factor of 100 within shortest time, while changes in Ultra Violet (UV) components of incoming radiation are even higher (Winther et al., submitted for publication).

The upward growth of sea ice from 0.78 to $0.84 \mathrm{~m}$ corresponds to an increase of $8 \%$ in total sea ice thickness. This emphasizes the importance of superimposed ice for the sea ice mass balance.

More important, by increasing ice thickness the presence of superimposed ice also extends the lifetime of the ice cover before it completely disappears. In Antarctica, Haas et al. (2001) reported the occurrence of floes consisting almost exclusively of superimposed ice. On Kongsfjorden, we observed such floes southwest of our measurement site on the more open fjord sections 
with deeper water. Over an area of several square kilometers, the original sea ice was very rotten or had completely disappeared and only an approximately 30 $\mathrm{mm}$ thick layer of superimposed ice with a rough, undulating surface was left. The sea ice had probably melted due to supposedly high ocean heat fluxes closer to the ice edge (Fig. 1). However, the low-salinity superimposed ice was almost unaffected by this because it floated in water with temperatures between -1.2 and $-0.6^{\circ} \mathrm{C}$.

The remaining of an ice cover composed of superimposed ice extends the ice season with raised surface albedo compared to the open water case when no ice is left any more. This shows how superimposed ice in fact plays an important role in modifying atmosphere-ocean processes.

At our measurement site at Gerdøya, however, we observed no sea-ice bottom melting. This can probably be explained by the sheltered location between the islands and by the only $22.5 \mathrm{~m}$ deep water preventing high ocean heat fluxes. Instead, melting was just observed at the surface, with the superimposed ice beginning to deteriorate after all snow had disappeared. This case seems to be typical for sea ice processes in the Central Arctic, or when ocean heat flux is generally small (Barber et al., 1998; Holt and Digby, 1985).

Our measurements have confirmed that snow melt on sea ice is detectable from spectral albedo. On sea ice in particular, this is indicative of superimposed ice formation. Therefore, superimposed ice formation could also well be observed from space using visible and infrared sensors like the Advanced Very High Resolution Radiometer (AVHRR). When albedo decreases also in the visible wavelengths, the disappearance of the snow could be inferred. Haas (2001) has shown that superimposed ice formation in Antarctica can also be derived from spaceborne scatterometer data, which show a distinct increase of radar backscatter during summer. However, this is only possible when snow melt is weak and episodic, and if the snow re-freezes again after melt events. With the conditions experienced on Kongsfjorden with a very wet surface, backscatter would rather drop and remain low over the summer, as typical for Arctic conditions (e.g. Winebrenner et al., 1998; Barber et al., 1998).

\section{Conclusions}

We performed quasi-continuous observations of superimposed ice formation on the fast ice of Kongsfjorden during the spring/summer transition in 2002 by simultaneously measuring snow properties and the atmospheric boundary conditions. Superimposed ice formed by downward percolation of melt water to colder, impermeable ice layers or the snow/ice inter- face, and by the settling of snow between those layers at melting temperatures. In the present case study longwave radiation played a major roll for initiating snow melt. We conclude that superimposed ice forms on sea ice upon any strong melt event, when freshwater can not drain otherwise. Thus, the process significantly contributes to the sea ice energy and mass balance.

We plan additional measurements at the same location under alternative meteorological conditions during the coming years in order to be able to generalize the above statements. Furthermore the results will allow to parameterize formation of superimposed ice and implement it in numerical models of different scale. The observations will be used to develop algorithms for superimposed ice detection from remote sensing data. With these, parameterizations over larger scales will be possible.

\section{Acknowledgements}

We are very grateful to the personnel of the Sverdrup and Koldewey stations for their great support, in particular Jon Arild Svenske, Jon Børre Ørbæk, Yvonne Kramer and Holger Pötschick. We thank Sebastian Gerland from the Norwegian Polar Institute for collecting the March ice core and important support on many other levels. Meteorological instrumentation and know-how was kindly provided by Gert König-Langlo and Bernd Loose, Alfred Wegener Institute, and by Alfred Helbig and Uwe Baltes, University of Trier. The study was performed at the Ny Alesund LSF under ECLSF grant NP-9/2001 and by additional financial support through German Research Council (DFG) project HA2724/3-1.

\section{References}

Andreas, E.L., Ackley, S.F., 1982. On the differences in ablation seasons of Arctic and Antarctic sea ice. Journal of Atmospheric Science 39 (2), 440-447.

Barber, D.G., Thomas, A., Papakyriakou, T.N., 1998. Role of SAR in surface energy flux measurements over sea ice. In: Tsatsoulis, C., Kwok, R. (Eds.), Analysis of SAR Data of the Polar Oceans: Recent Advances. Springer-Verlag, Berlin, pp. 35-67.

Colbeck, S.C., 1987. Theory of particle coarsening with a log-normal distribution. Acta Metallurgica 35 (7), 1583-1588.

Eicken, H., Fischer, H., Lemke, P., 1995. Effects of the snow cover on Antarctic sea ice and potential modulation of its response to climate change. Annals of Glaciology 21, 369-376.

Gerland, S., Winther, J.-G., Ørbæk, J.B., Ivanov, B.V., 1999. Physical properties, spectral reflectance and thickness development of first year fast ice in Kongsfjorden, Svalbard. Polar Research 18 (2), 275-282.

Haas, C., 2001. The seasonal cycle of ERS scatterometer signatures over perennial Antarctic sea ice and associated surface ice properties and processes. Annals of Glaciology 33, 69-73. 
Haas, C., Thomas, D.N., Bareiss, J., 2001. Surface properties and processes of perennial Antarctic sea ice in summer. Journal of Glaciology 47, 613-625.

Holt, B., Digby, S.A., 1985. Processes and imagery of first-year fast sea ice during the melt season. Journal of Geophysical Research 90 (C3), 5045-5062

Jeffries, M.O., Worby, A.P., Morris, K., Weeks, W.F., 1997. Seasonal variations in the properties and structural composition of sea ice and snow cover in the Bellinghausen and Amundsen Sea, Antarctica. Journal of Glaciology 43 (143), 138-151.

Kawamura, T., Ohshima, K.I., Takizawa, T., Ushio, S., 1997. Physical, structural and isotopic characteristics and growth processes of fast sea ice in Lützow-Holm Bay, Antarctica. Journal of Geophysical Research 102 (C2), 3345-3355.

Koerner, R.M., 1970. Some observations on superimposition on ice on the Devon Island Ice Cap, N.W.T., Canada. Geografiska Annaler 52A, 57-67.

König, M., Winther, J.-G., Isaksson, E., 2001. Measuring snow and glacier ice properties from satellite. Reviews of Geophysics 39, $1-27$.

Launiainen, J., Cheng, B., 1995. A simple non-iterative algorithm for calculating turbulent bulk fluxes in diabatic conditions over water snow/ice and ground surface. In: Report Series in Geophysics, vol. 33. Department of Geophysics, University of Helsinki.
Massom, R.A., Drinkwater, M.R., Haas, C., 1997. Winter snow cover on sea ice in the Weddell Sea. Journal of Geophysical Research 102 (C1), 1101-1117.

Onstott, R., 1992. SAR and scatterometer signatures of sea ice. In: Microwave Remote Sensing of Sea IceCarsey, F.D. (Ed.), No. 68 in Geophysical Monograph Series. American Geophysical Union, Washington, DC, pp. 73-104.

Sihvola, A., Tiuri, M., 1986. Snow fork for field determination of the density and wetness profiles of a snow pack. IEEE Transactions on Geoscience and Remote Sensing GE 24 (5), 717-721.

Svendsen, H., Beszczynska-Møller, A., Hagen, J.O., Lefauconnier, B., Tverberg, V., Gerland, S., Ørbæk, J.B., Bischof, K., Papucci, C., Zajaczkowski, M., Azzolini, R., Bruland, O., Wiencke, C., Winther, J.-G., Dallmann, W., 2002. The physical environment of Kongsfjorden-Krossfjorden, an Arctic fjord system in Svalbard. Polar Research 21 (1), 133-166.

Winebrenner, D.P., Long, D.G., Holt, B., 1998. Mapping the progression of melt onset and freeze-up on Arctic sea ice using SAR and scatterometry. In: Tsatsoulis, C., Kwok, R. (Eds.), Analysis of SAR Data of the Polar Oceans: Recent Advances. Springer-Verlag, Berlin, pp. 129-144.

Winther, J.-G., Edvardsen, K., Gerland, S., Hamre, B. Surface reflectance of sea ice and under-ice irradiance in Kongsfjorden, Svalbard. Polar Research, submitted for publication. 